\title{
Surgery of Chronic Post Traumatic Boutonniere Deformity: Results of 12 Cases Treated By Dorsalizing the Lateral Bands and Tightening the Central Slip with Literature Review
}

\author{
Hatim Abid*, Mohammed El Idrissi, Abdelhalim El Ibrahimi, Abdelmajid Elmrini
}

Department of Osteoarticular Surgery B4, HASSAN II teaching hospital, Fes, Morocco

DOI: $10.36347 /$ sasjs.2020.v06i10.007

| Received: 27.09.2020 | Accepted: 12.10.2020 | Published: 28.10.2020

*Corresponding author: Abid Hatim

\section{Abstract}

We report the results of 12 patients followed for post traumatic and chronic boutonniere deformity treated by dorsalizing the lateral bands and tightening the central slip. Thanks to its multiple technical and biomechanical advantages, this procedure allowed 10 patients to recover a near complete curling of the finger with a pulp-to-palm distance less than $0.5 \mathrm{~cm}$. The average residual active extension defect was 9 degrees.

Keywords: Boutonniere deformity; post traumatic; surgery.

Copyright $(\mathcal{C}) 2020$ The Author(s): This is an open-access article distributed under the terms of the Creative Commons Attribution 4.0 International License (CC BY-NC 4.0) which permits unrestricted use, distribution, and reproduction in any medium for non-commercial use provided the original author and source are credited.

\section{INTRODUCTION}

One of the earliest descriptions of the boutonniere deformity of the hand extensor mechanism was detailed by Gustav Hauck in 1923 [1]. It corresponds to a deformity where the proximal interphalangeal (PIP) joint of the finger is flexed, and the distal interphalangeal (DIP) joint is hyperextended $[2,3]$. Commonly, boutonniere deformity is seen most often in post traumatic context and as a sequela of inflammatory rheumatism [2, 3]. Various techniques have been described to address the imbalance between the extensor and flexor mechanism. We report the results of a series of 12 patients treated by dorsalizing the lateral bands and tightening the central slip.

\section{PATIENTS AND METHOD}

The boutonniere deformity (Figure-1) surgery by dorsalizing the lateral bands and tightening the central slip was performed in 12 patients between 2017 and 2020. The surgery was practiced by two senior hand surgeons. At the time of the latest follow-up, all patients underwent full clinical examination by the authors. Preoperative data were obtained from hospital records. The intervention was carried as outpatient surgery under pneumatic tourniquet and pure sensory distal nerve block. To expose the extensor system, the surgeons performed a dorsal curvilinear incision centered on DIP joint. First we practiced a tenoarthrolysis of the PIP that was associated to palmar arthrolysis through the same dorsal incision in case of passively irreducible deformities. Then the central slip was tightened by crossstitches with lateral bands dorsalization. If necessary, an elongation of the lateral bands was performed with a scalpel by staged punctiform tenotomy to obtain the maximal active extension. At the end of the surgery, there was no pinning or splinting immobilization. Postoperatively, the assessment of pain and function was evaluated according to the Quick Dash (Disabilities of the Arm, Shoulder and Hand) Score. Concerning the range of movement, we measured it using a goniometer.

\section{RESULTS}

In our series, there were 8 men and 4 women. The deformation was exclusively post traumatic. The mean age was 37 years (range of 19 to 62 years), and the mean duration of follow-up was 18 months. The mean time interval between initial injury and surgery was 4 months. Patients were considered for surgery because of an active extension defect of the PIP joint which was 60 degrees on average for stiff and flexible boutonniere without osteoarthritis after conservative treatment failure. According to the classification of Boutonniere deformities [4] there were 7 deformities stage 1, 3 deformities stage 2, and 2 deformities stage 3 . Four stiff deformities were noted and were passively irreducible. The average pulp-to-palm distance was 2 $\mathrm{cm}$. At the last follow-up ten patients recovered a near complete curling of the finger (Figure 2 and 3) with a pulp-to-palm distance $<0.5 \mathrm{~cm}$. The average active flexion of the DIP was 80 degrees. For the PIP, the 
average residual active extension defect was 9 degrees (Table-1).

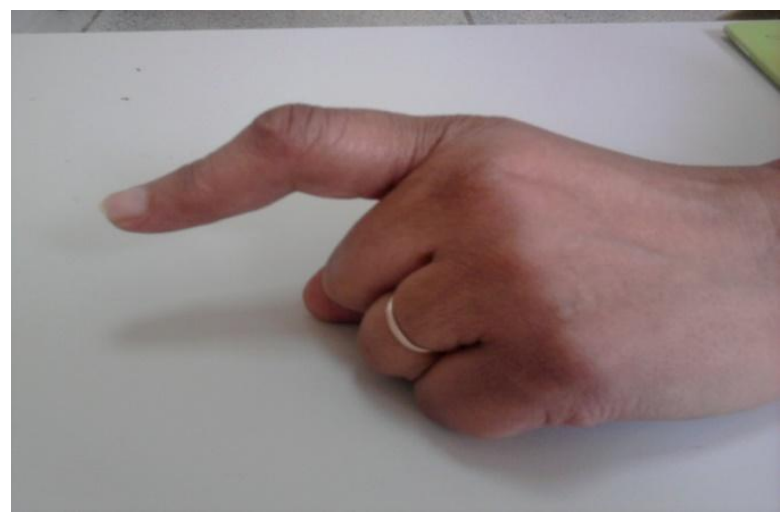

Fig-1: Boutonniere deformity after conservative treatment failure

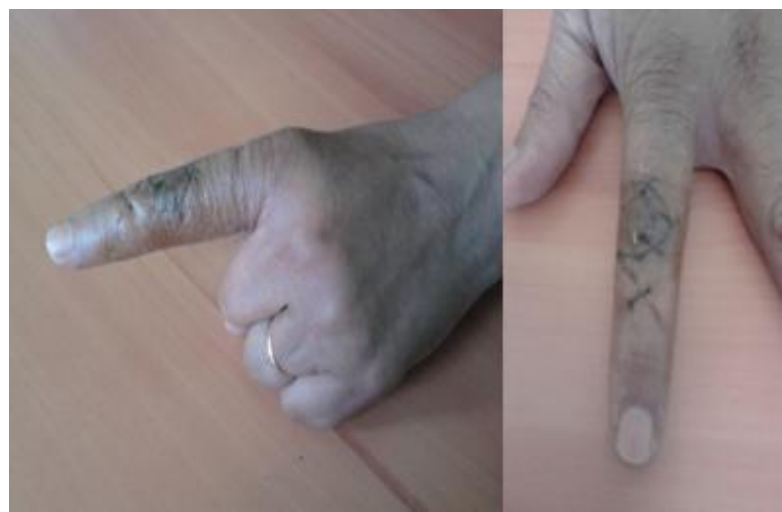

Fig-2: Clinical aspect at 3 weeks to surgery

\section{DISCUSSION}

Injury of the extensor tendon prevents the finger from active extension at the PIP joint. The extensor tendon injury includes central slip rupture, triangular ligament attenuation and lateral band volar migration [2, 3]. Stressing the extensor mechanism, the PIP and DIP are subject respectively to a pathologic flexion and extension forces responsible for the characteristic boutonniere deformity [5]. From a therapeutic point of view, attitudes are divided between conservative treatment and surgery, mainly depending on the duration of deformity installation, its flexibility or passively irreducibility and its response or not to conservative treatment.

In the litterature, many surgeons consider the results of surgical treatment unpredictable, for this, they try first splint immobilization in extension before proposing surgery. In the case of acute and flexible boutonniere deformities, the PIP is splinted continuously in extension for 6 weeks, with the DIP free to flex to stretch out the contracted lateral bands. In this context, Souter et al., [2] reviewed retrospectively 65 patients with central slip injuries. Satisfactory results were reported in 31 patients. The authors conclued that conservative treatment within 6 weeks of injury was associated with good results.

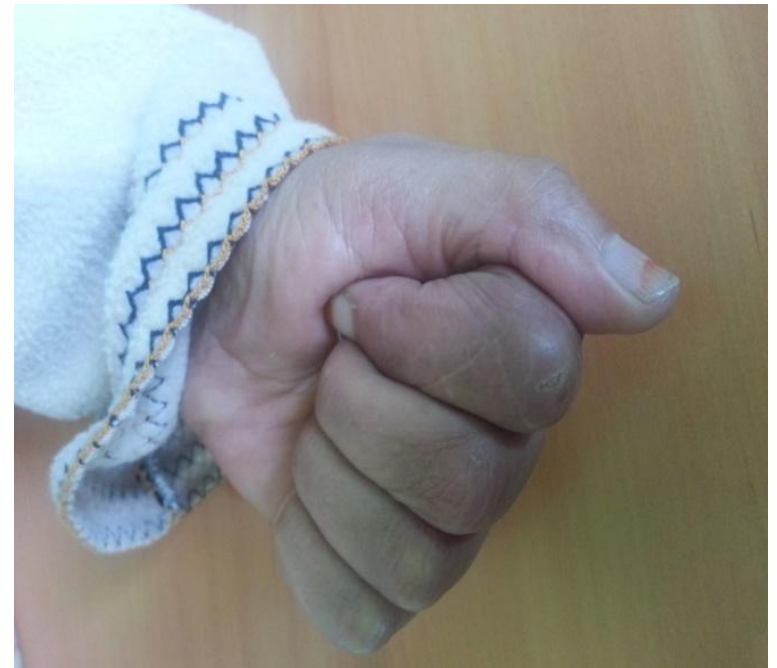

Fig-3: Near complete curling of the index at 3 months to surgery

Table-1: Residual active extension defect and Quick Dash Score at the last follow-up

\begin{tabular}{|c|c|c|}
\hline Patient & PIP extension defect $\left(^{\circ}\right)$ & Quick Dash score (0-100) \\
\hline 1 & 3 & 4.2 \\
\hline 2 & 5 & 7.6 \\
\hline 3 & 7 & 0 \\
\hline 4 & 35 & 23 \\
\hline 5 & 0 & 0 \\
\hline 6 & 4 & 6.5 \\
\hline 7 & 0 & 2.8 \\
\hline 8 & 10 & 14.5 \\
\hline 9 & 6 & 0 \\
\hline 10 & 5 & 4.8 \\
\hline 11 & 40 & 29 \\
\hline 12 & 0 & 0 \\
\hline
\end{tabular}

Regarding surgical treatment, it includes reattachment of the central slip and various methods of lateral band reconstructions. Most of surgical procedures described in the literature [6-9], are most often complex and require postoperative immobilization for 2 to 6 weeks depending on the authors. They are classically contra-indicate in the case of joint stiffness.

In this context, Dolphin [10] first reported in 1965 the use of the extensor tenotomy that is sectioned obliquely just distal to the triangular ligament to correct chronic boutonniere deformity in 2 patients. The same procedure was performed and descriped by Stern [7] in 1989 and Meadows et al [6] in 1995. Both series included 13 patients who had improved in the majority of cases their DIP joint flexion and PIP joint extension.

Suzuki [11] described in 1973 a method previously described by Flatt in 1963 . First, the authors excised the scarred extensor apparatus over the PIP joint. Then an hexagonal sheet of the fascia with the palmaris longus tendon are removed. The palmaris longus is sutured proximally to the end of the extensor digitorum communis tendon and distally to the insertion of the central slip on the middle phalanx. The sleeve of fascia is passed beneath the remaining of the lateral 
bands on both sides and sutured to each other. Of 11 patients, only 3 had good results.

In terms of reattachment of the central slip, Rothwell [12] descriped in 1978 a technique which consists in central slip mobilization after its dissection along the whole of the proximal phalanx, and its attachement into the base of the middle phalanx. The subluxed lateral slips are released sufficiently then displaced dorsally to their anatomical position. The proximal joint is then stabilised in full extension by a fine Kirschner wire. This technique had been used by the author [11] in a consecutive series of twelve cases. In ten patients the results were excellent, with full active flexion and extension at both interphalangeal joints.

In 1979, Pardini et al., [13] reported the results of a series of 25 patients treated with central slip scar tissu excision and end-to-end repair. The authors realized lateral bands dissection. The fibrous tissue that replaced the central tendon is removed. The central tendon is advanced after PIP joint immobilization in full extension by crossed Kirschner wires and sutured to its stump at the base of the middle phalanx. The lateral bands are then suspended and sutured to the lateral margin of the central tendon. If necessary the triangular ligament is plicated. Until the last follow-up, the results were good in $59 \%$ of the cases.

Urbaniak et al., [14] described in 1981 central slip reconstruction using a triangular flap and local tissue. In their technique, a triangular flap is elevated between the lateral bands. Another capsular flap attached to the base of the middle phalanx, is passed through a split in the proximally based flap and sutured to the extensor tendon. Of 13 patients, 8 had good results.

Curtis et al [8] described in 1983 staged procedures in the correction of chronic traumatic boutonniere deformity. Stage I consisted of freeing the transverse retinacular ligament associated to a tenolysis of the extensor tendon. When full extension is not obtained, the authors proceeded to stage II, in which the transverse retinacular ligament was transected near the lateral band. For an extension deficit of $20^{\circ}$ or less, stage III is indicated. The surgeons practiced extensor tenotomy. In the case of an extension deficit of $20^{\circ}$ or more, the surgeons realized stage IV, represented by excising central slip scar tissue and performing an endto-end repair with dorsal imbrications of lateral band to the central slip. Of 23 patients, 20 patients had improved DIP joint flexion postoperatively.

In 1990, Caroli et al., [15] described their procedure which consists to an excision of swallowtailed flap of the fibrous tissue, taking care to leave a short edge of the scarred capsular tissue at the phalangeal insertion to assure anchoring of the proximal edge of the central slip after determining the correct length of the central tendon. In the same way as the most other techniques, full extension is maintained with Kirschner wire. Of the 18 patients, the authors reported 13 excellent results. Ohshio et al., [16] described in the same year (1990) a technique in which the transverse retinacular ligaments are separated from their insertion at the palmar plate, turned over the dorsal aspect on the PIP joint to lift the lateral band and sutured to one another. The PIP joint is fixed in extension with a Kirschner wire. In 4 digits, 3 improved with an extension deficit of $5^{\circ}$.

Recently, Dubois et al., [17] reported in 2017 a series of 11 patients treated for chronic boutonniere deformity with a dorsal incision, an extensor tenolysis, central slip tightening and lateral bands dorsalization over the PIP joint. To obtain the maximal of active extension, the authors realized lengthening of the lateral bands by punctiform tenotomy. At the end of the surgery, there was no immobilization as is necessary with the others techniques. According to its authors, this technique uses the elastic properties of the elongation and allows immediate mobilization. Thanks to this procedure, the deformity whether supple or stiff, was improved in 10 patients with a total finger flexion.

In our daily practice and taking into account its multiple technical and biomechanical advantages (simple, reproducible and dynamic), the lateral bands lengthening and dorsalization, associated to central slip tightening with early mobilization as descriped by Dubois et al., [17] represents our procedure of choice to treat both supple and stiff chronic boutonniere deformity. Thanks to this technique, ten of our patients recovered a near-complete curling of the finger with a pulp-to-palm distance $<0.5 \mathrm{~cm}$. The average of residual PIP active extension defect was 9 degrees.

\section{CONCLUSION}

The lateral bands lengthening and dorsalization, associated to central slip tightening with early mobilization represents a simple, reliable and reproducible surgical technique for the management of supple and stiff chronic boutonniere deformity after conservative treatment failure. With great conviction, we practice this procedure in the perspective to a large and prospective series.

No benefits or funds were received in support of this study

The authors report no conflict of interests.

\section{REFERENCES}

1. Hauck G. Die Ruptur der Dorsalaponeurose am ersten Interphalangealgelenk, zugleich ein Beitrag zur Anatomic und Physiologic der Dorsalaponeurose. Arch Klin chir. 1923; 123:197. 
2. Souter WA. The problem of boutonniere deformity. Clin Orthop. 1974; 104:116-33.

3. Coons MS, Green SM. Boutonniere deformity. Hand Clin. 1995; 11(3):387-402.

4. Burton RI. Extensor tendons-late reconstruction. In: Green DP, ed. Operative Hand Surgery. New York, NY: Churchill Livingstone; 1988:20732116.

5. Elzinga K, Chung K C. Managing Swan Neck and Boutonniere Deformities. Clin Plast Surg. 2019; 46(3):329-337.

6. Meadows SE, Schneider LH, Sherwyn JH. Treatment of the chronic Boutonniere deformity by extensor tenotomy. Hand Clin. 1995; 11:441447.

7. Stern PJ. Extensor tenotomy: a technique for correction of posttraumatic distal interphalangeal joint hyperextension deformity. J Hand Surg Am. 1989; 14:546-549.

8. Curtis RM, Reid RL, Provost JM. A staged technique for the repair of the traumatic Boutonniere deformity. J Hand Surg Am. 1983; 8:167-171.

9. Towfigh H, Gruber P. Surgical treatment of the Boutonnie`re deformity. Oper Orthop Traumatol. 2005; 17:66-78.
10. Dolphin JA. Extensor tenotomy for chronic boutonnière deformity of the finger; report of two cases. J Bone Joint Surg. 1965; 47A:161-164.

11. Suzuki K. Reconstruction of post-traumatic boutonnière deformity. Hand. 1973; 5:145-148.

12. Rothwell AG. Repair of the established post traumatic boutonnière deformity. Hand. 1978; 10:241-245.

13. Pardini AG, Costa R, Morais MS. Surgical repair of the boutonnière deformity of the fingers. Hand. 1979; 11:87-92.

14. Urbaniak JR, Hayes MG. Chronic boutonnière deformity - an anatomic reconstruction. J Hand Surg. 1981; 6:379-383.

15. Caroli A, Zanasi S, Squarzina PB, Guerra M, Pancaldi G. Operative treatment of the posttraumatic boutonnière deformity: a modification of the direct anatomical repair technique. J Hand Surg. 1990; 15B:410-415.

16. Ohshio I, Ogino $\mathrm{T}$, Minami A, Kato $\mathrm{H}$. Reconstruction of the central slip by the transverse retinacular ligament for boutonnière deformity. $\mathrm{J}$ Hand Surg, 1990; 15B:407-409.

17. Dubois E, Teboul F, Bihel T, Goubier J N. Chronic Boutonniere Deformities, Supple, or Stiff: A New Surgical Technique With Early Mobilization in 11 Cases. Tech Hand Surg. 2017; 21: $37-40$. 